\title{
The Empirical Study of how Transport Infrastructure Influence Guangdong's Economic based on Dynamic Spatial Panel Data Model
}

\author{
Ting $\mathrm{He}$
}

South China University of Technology, Economic and trade institute

Panyu, Guangzhou, Guangdong, China

ht_scut@163.com

Keywords: Transport infrastructure; spatial spillover effect; Spatial Durbin model; Spatial Dynamic Panel Model

\begin{abstract}
The article adopts 21 regions of Guangdong province from 2005 to 2014, the panel data of ten years, to study how transportation infrastructure affects its economic growth. At first, this paper use the exploratory space analysis method to research spatial pattern and spatial correlation of transportation infrastructure and economic development in Guangdong province, then adopting Spatial Durbin Model to analyze the difference of transportation infrastructure spillover effects in different areas of Guangdong province, secondly adopting Dynamic Spatial Panel Data Model to analyze spatial spillover effects of the transport infrastructure in Guangdong province, finally, provide suggestions to transport infrastructure investment in Guangdong province.
\end{abstract}

\section{基于动态空间面板模型的交通基础设施对广东省经济增长的影响的实 证研究}

\author{
何婷 \\ 华南理工大学经济与贸易学院, 番禺, 广州, 广东, 中国 \\ ht_scut@163.com
}

关键词: 交通基础设施；空间溢出效应；空间杜宾模型；空间动态面板模型

摘要. 文章采用广东省 21 个地区 2005 至 2014 十年的面板数据研究广东省交通基础设施对其 经济增长的影响。首先采用探索性空间分析方法研究广东交通基础设施与经济发展的空间格 局和空间自相关性，然后用空间杜宾模型分析交通基础设施在广东省不同区域空间溢出效应 的差异，其次采用动态空间面板数据模型分析广东省交通基础设施的空间溢出效应。最后对 广东省交通基础设施投资提供建议。

\section{1.引言}

\section{1 选题的背景}

近年来广东经济迅猛发展, 交通基础设施建设成效显著, 有必要研究交通基础设施与经 济增长之间的关系。

\section{2 选题的意义}

本文选取广东作为研究对象, 具有典型性。同时, 本文以地级市为研究单元, 丰富了研 究内容。以往研究多以静态研究为主, 本文研究交通基础设施空间溢出效应的动态变化。 
2.广东省交通基础设施与经济增长的空间格局和空间自相关性

\section{1 广东省经济的空间格局和空间自相关性}
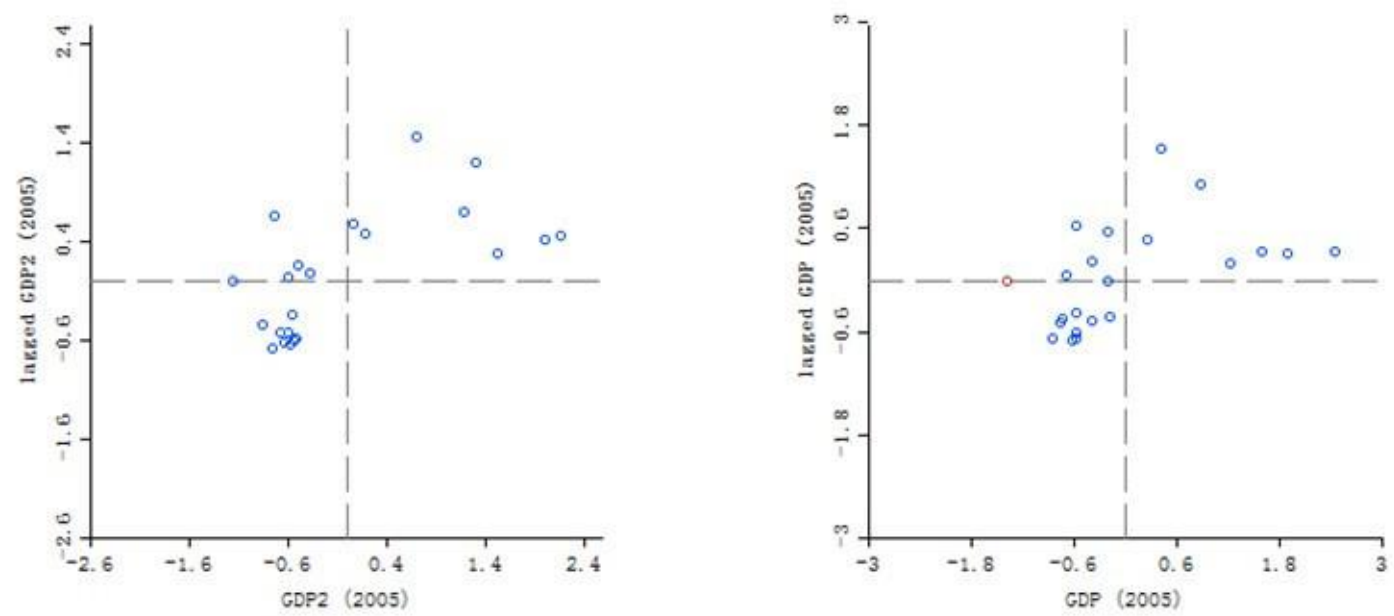

图1 2005、2014 年广东人均 GDP 的 Moran's I 散点图

无论是2005年还是2010 年, 呈现正向空间关联地区的比重都远大于呈现非空间关联地区 的比重，说明广东区域经济存在明显的空间依赖性。

\section{2 广东省交通基础设施的发展趋势与空间格局分析}
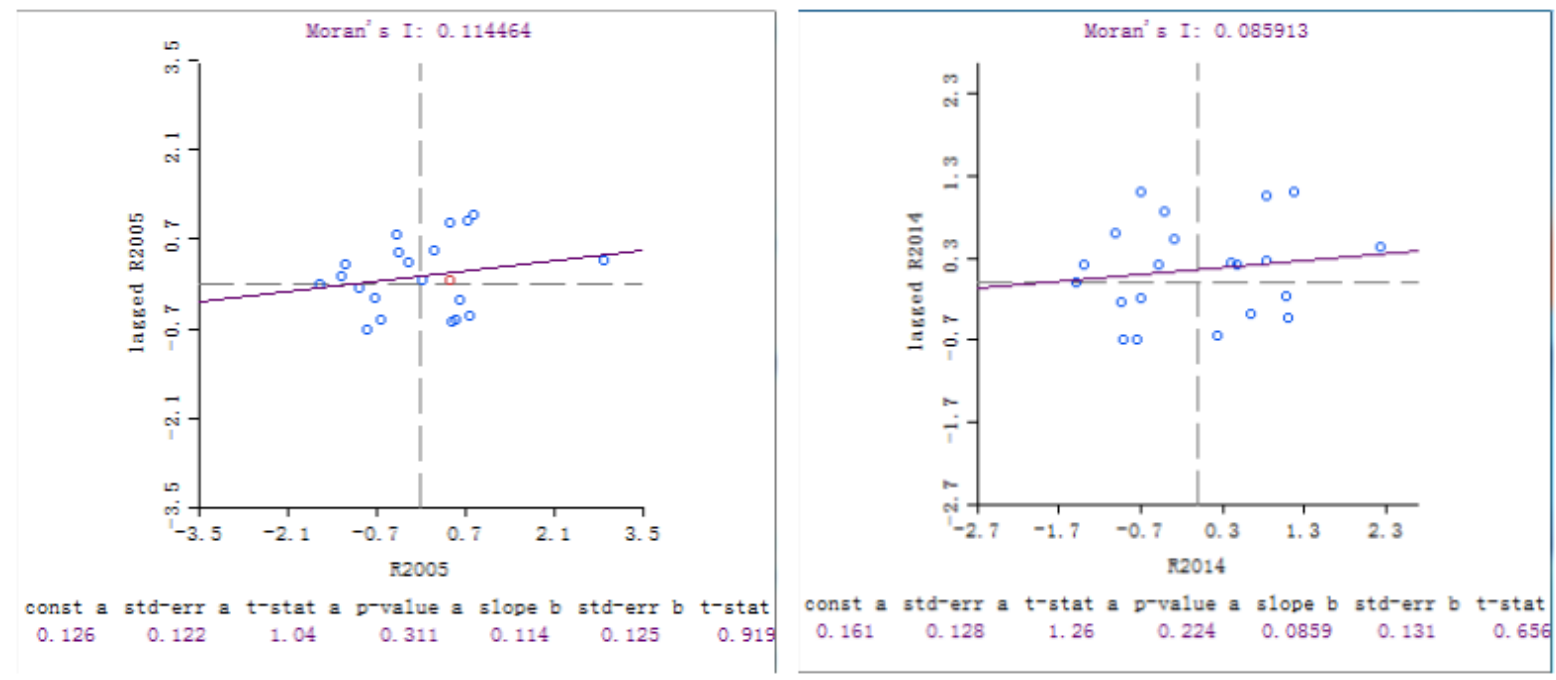

图2２005、2014年广东交通基础设施营运里程的Moran's I散点图

无论是2005年还是 2014 年，呈现正向空间关联地区的比重仍然都大于呈现非空间关联地 区的比重, 说明广东省交通基础设施建设的现状存在一定程度的空间依赖性。

\section{3. 交通基础设施对广东省经济增长空间溢出效应的实证分析}

\section{1 空间溢出效应模型的构建}

3.1 .1 模型设定形式

(1) 固定效应模型 


$$
\ln Y_{i t}=\lambda W_{i j} \sum_{\mathrm{j}=1}^{n} \ln Y_{i t}+\alpha_{0}+\alpha_{1} \ln L_{i t}+\alpha_{2} \ln K_{i t}+\alpha_{3} \ln T_{i t}+\mu_{i t}
$$

（2）空间杜宾模型

$$
\ln Y_{i t}=\lambda W_{i j} \sum_{\mathrm{j}=1}^{n} \ln Y_{i t}+\alpha_{0}+\alpha_{1} \ln L_{i t}+\alpha_{2} \ln K_{i t}+\alpha_{3} \ln T_{i t}+\rho W_{i j} \sum_{j=1}^{n} \ln T_{i j t}+\mu_{i t}
$$

（3）空间动态面板模型

$$
\ln Y_{i t}=\lambda W_{i j} \sum_{\mathrm{j}=1}^{n} \ln Y_{i t-1}+\alpha_{0}+\alpha_{1} \ln L_{i t}+\alpha_{2} \ln K_{i t}+\alpha_{3} \ln T_{i t}+\rho W_{i j} \sum_{j=1}^{n} \ln T_{i j t}+\gamma_{i}+\mu_{i t}
$$

\section{2 模型估计及实证分析}

\begin{tabular}{|c|c|c|c|}
\hline 模型 & 固定效应模型 & 空间杜宾模型 & 动态空间面板模型 \\
\hline $\ln Y$ & \multicolumn{3}{|c|}{ 被解释变量 } \\
\hline \multirow{2}{*}{ InK } & $0.489^{* * *}$ & $0.460^{* * *}$ & $0.455^{* * *}$ \\
\hline & $(22.23)$ & $(16.36)$ & -10.56 \\
\hline \multirow{2}{*}{$\ln L$} & $0.227^{* * *}$ & $0.232^{* * *}$ & $0.229^{* * *}$ \\
\hline & (1.81) & (11.09) & -10.09 \\
\hline \multirow{2}{*}{$\ln T$} & $0.189^{* * *}$ & $0.242^{* * *}$ & $0.256^{* * *}$ \\
\hline & $(8.21)$ & $(10.8)$ & -12.8 \\
\hline \multirow{2}{*}{ WInY } & $0.136^{* * *}$ & $0.303^{* * *}$ & \\
\hline & $(11.86)$ & (10.03) & \\
\hline \multirow{2}{*}{ WInYit-1 } & & & $0.417^{* * *}$ \\
\hline & & & -12.06 \\
\hline \multirow{2}{*}{ WInT } & & $0.105^{* * *}$ & $0.126^{* * *}$ \\
\hline & & (11.08) & -16.22 \\
\hline \multirow{2}{*}{$\alpha_{0}$} & $-2.439^{*}$ & $-1.907^{* *}$ & $-2.814^{* *}$ \\
\hline & (1.89) & (2.01) & -4.06 \\
\hline 调整的 $R^{2}$ & 0.143 & 0.032 & 0.037 \\
\hline 对数似然值 & 539.251 & 663.767 & 683.977 \\
\hline
\end{tabular}

\subsection{1 广东省估计结果}

表1 不同模型的估计结果

注: 括号内数字为相应的 $\mathrm{z}$ 统计量, * *** 和*** 分别表示在 $1 \%$ 、 $5 \%$ 和 $10 \%$ 的水平上显著。

（1）模型整体的拟合优度较高，调整 $R^{2}$ 均达到，空间动态面板模型的对数似然函数值高 于空间杜宾模型，高于普通面板模型, 意味着将交通基础设施对经济发展的空间溢出效应引入 模型更为合适。

(2) 从空间杜宾模型的估计结果来看, 交通基础设施的直接产出弹性为 0.242 , 间接产 出弹性为 0.105 . 总产出弹性为 $0.242+0.105=0.347$, 间接效应在总效应中占比 $30.3 \%$ 。这意味 着2005 2014年间广东省交通基础设施投资每增加1个百分点, 产出的增加将达到 $34.7 \%$, 其 中， $10.5 \%$ 来源于交通基础设施投资的空间溢出效应。

（3）空间动态面板数据模型的回归结果显示交通基础设施建设水平对经济增长产生了高 度显著的正作用, 显著性水平为 $1 \%$, 表明区域经济增长对于经济发展水平和交通基础设施投 
资具有很大的依赖性。本区域对于周边邻近区域经济的增长产生了正面的影响, 但也较不显 著, 说明本地经济增长对邻近地区的经济增长作用较小, 地区间的扩散效应和收玫效应大致 相当。

\section{4.结论}

首先交通基础设施不仅能够促进本地区的经济增长，还能通过一种空间溢出效应促进临 近地区的经济发展。其次, 直接效应大于间接效应, 不同地区对交通基础设施的利用效率存 在差异。

\section{References}

[1] Berechman Joseph, Ozbay Ozmen -Ertekin, Empirical Analysis of Transportation Investment and Economic Development at State, Country and Municipality levels, Transportation, 2006 (33): 537-551.

[2] [9] Grimes, A., \& Young, C. Spatial effects of urban upgrades [J]. Journal of Transport Geography, 2013(30): 1-6. 